\title{
Optimizing the effect of charging electric vehicles on distribution transformer using demand side management
}

\author{
Swapna Ganapaneni, Srinivasa Varma Pinni
}

Department of Electrical and Electronics Engineering, Koneru Lakshmaiah Education Foundation, Guntur, India

\begin{tabular}{|c|c|}
\hline Artic & ABSTRACT \\
\hline Article history: & \multirow{6}{*}{$\begin{array}{l}\text { This paper mainly aims to present the demand side management (DSM) of electric ve- } \\
\text { hicles (EVs) by considering distribution transformer capacity at a residential area. The } \\
\text { objective functions are formulated to obtain charging schedule for individual owner } \\
\text { by i) minimizing the load variance and ii) price indicated charging mechanism. Both } \\
\text { the objective functions profit the owner in the following ways: i) fulfilling their needs } \\
\text { ii) minimizing overall charging cost, iii) lessening the peak load, and iv) avoiding } \\
\text { the overloading of distribution transformer. The proposed objective functions were } \\
\text { worked on a residential area with } 8 \text { houses each house with an EV connected to a } \\
20 \mathrm{kVA} \text { distribution transformer. The formulations were tested in LINGO platform- } \\
\text { optimization modeling software for linear, nonlinear, and integer programming. The } \\
\text { results obtained were compared which gives good insight of EV load scheduling with- } \\
\text { out actual price prediction. }\end{array}$} \\
\hline Received Mar 14, 2021 & \\
\hline Revised Oct 27, 2021 & \\
\hline Accepted Nov 26, 2021 & \\
\hline Keywords: & \\
\hline $\begin{array}{l}\text { Charging } \\
\text { Demand side management } \\
\text { Distribution transformer } \\
\text { Electric vehicle }\end{array}$ & \\
\hline
\end{tabular}

This is an open access article under the CC BY-SA license.

Over loading

Scheduling

\section{Corresponding Author:}

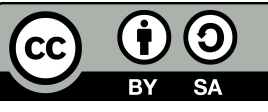

Swapna Ganapaneni

Department of Electrical and Electronics Engineering, Koneru Lakshmaiah Education Foundation

Green Fields, Vaddeswaram, Guntur District, Andhra Pradesh, 522502, India

Email: swapna@kluniversity.in

\section{INTRODUCTION}

Electric vehicle $(\mathrm{EV})$ is the one can satisfy the need of future transportation due to lack of enough fossil fuels which tops the demand for electrical energy. In such a situation if charging and discharging of EVs are not handled properly will overloads the grid. In this regard charging the EV at residential places is a key issue resulting in several technical problems at the level of distribution transformer, demand side management (DSM) is possibly a good solution.

An overview on the literature of DSM techniques is presented here. Rapid increase in day to day electricity demand, DSM helps to avoid utilities building extra capacity of the generation by means of decreasing the peak demand through shifting and adjusting customers electricity consumption. DSM mainly involves three programs like efficient energy management (EM), demand response (DR), effective load management (ELM) by the customers [1]. Figure 1 represents the detailed classification of DSM.

Energy management (EM) mainly aims to reduce energy consumption which automatically minimizes the energy cost. A good scope of energy management can be easily achieved in various sectors like industrial, commercial, agricultural and even in households if energy saving tips are followed. Proper maintenance of boilers, steam systems, compressed air systems, motor and drive systems, and lightening aspects, will lowers the energy usage. Time to time audit of energy; awareness and training programs; and good metering and billing systems, are the important aspects through which efficient energy management is obtained [1].

Demand response (DR) is one important policy of DSM which concentrates mainly on the pricing 
system to manage the peak load. DR denotes "changes in electric usage by end-use customers from their normal consumption patterns in response to changes in the price of electricity over time, or to incentive payments designed to induce lower electricity use at times of high wholesale market prices or when system reliability is jeopardized" [2].

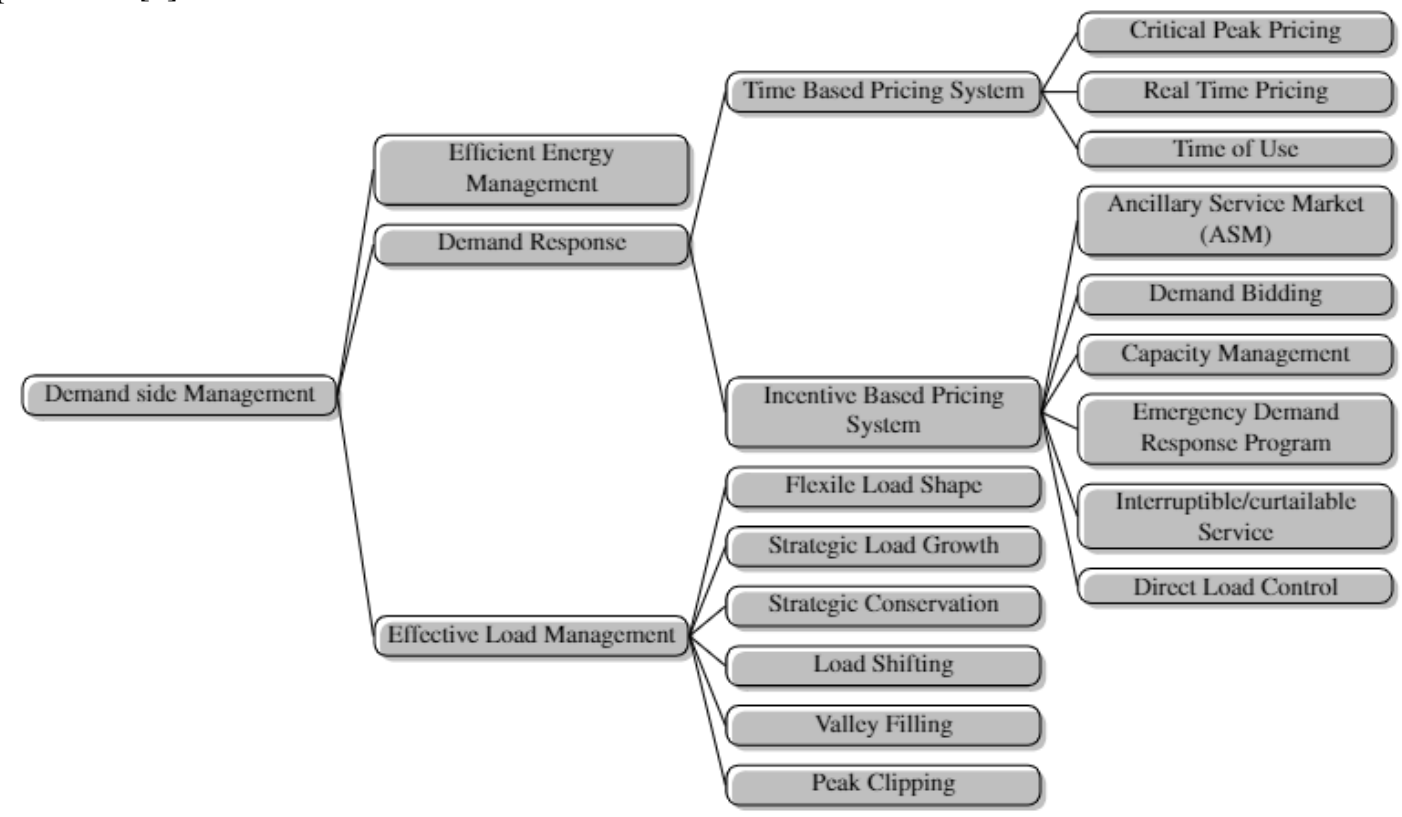

Figure 1. Classification of demand side management techniques

Two major classification are done in the DR programs based on the pricing system are time-based pricing system (TBPS) and incentive-based pricing system (IBPS) [3]. Direct load control (DLC), interruptible/curtailable service (I/CS), emergency demand response program (EDRP), capacity management (CM), demand bidding (DB), ancillary service market (ASM) are classified under IBPS whereas time of use (ToU), real time pricing (RTP), critical peak pricing (CPP) are categorized under TBPS.

- Direct load control (DLC): DLC is one approach of DR where customer's loads are shuts down by the utilities remotely on short notice for reliability problems. This is mainly executed on small consumers like residential and small commercial customer [4].

- Interruptible/curtailable service (I/CS): It is the program where customers on curtail of their equipment gets a discount or credited on their bill when the system is under contingency and if they do not agree to curtail, they are penalized.

- Emergency demand response program (EDRP): When an event occurs, emergency DR is a usual program to implement. In the case of reliability events EDRP offers incentives to customers for reducing their loads and cannot be penalized for not curtailing their load because the prices are pre-specified [5].

- Capacity management (CM): It is a demand side resource, during contingencies it commits to reduce pre specified amount of load and penalizes the participants if they do not curtail the load on instructions. Customers obliging the instructions are guaranteed to receive payments in exchange.

- ToU: Prices are set in advance but differs depending on the times of the day and will not reflect any adjustments to the actual conditions of the system. Consumers will not have any incentives for reduced consumption in electricity during peak periods and hourly metering is not required.

- RTP: It is also termed as dynamic pricing as prices varies with real time conditions and reflects the actual phenomenon of the system by providing best information about the power available at a location. Energy consumption should be measured on hourly basis as it is charged appropriately, and customers are offered with incentives for their reduced consumption of energy during peak periods.

- CPP: This is a dynamic pricing scheme where few peak hours are charged with high prices to reduce peak demand and other time periods are charged with normal prices, there by permits the customers to minimize their overall energy bill. 
Effective load management (ELM) techniques are the one where utility tries to reduce the peak consumption by the subsequent approaches like peak clipping, valley filling, load shifting, strategic conservation, strategic load growth, flexible load shape [6].

- Peak clipping: It is the way where load is reduced during peak time by means of DLC like shutting down the equipment of the consumer. This method will not greatly influence the entire load curve but reflects in reduction of load during peak period.

- Valley filling: It encourages energy consumption during off peak hours by the customers over offering incentives like allowing them to pay low tariff for changing their schedule to off peak hours, and discounts.

- Load shifting: This method aims to shift the load during peak hours to period where load is lessened however overall demand remains constant in this phenomenon.

- Strategic conservation: It mainly drives to bring down seasonal energy consumption by encouraging consumers towards the use of efficient devices and appliances, decreasing wastage of energy. It also offers incentives to consumers who adopts technological changes in their usage.

- Strategic load growth: It mainly tries to control seasonal increase in energy consumption. The dealership employs intelligent systems, effective devices and more viable sources of energy to reach their goals.

- Flexible load shape: It includes set of activities and integrated planning between concessionary and the customer rendering to the requirement of the moment. Consumer loads are modeled with the help of load limiting equipment such that there will not be much deviation in the actual load and will not disturb security issues.

Upgrading the distribution transformer with penetration of EV in the distribution system is a cost expensive and unplanned charging of these EVs may cause the grid overloading. Therefore, a strategy DR is applied to avoid overloading of transformers by considering the priority of each individual home and convenience preference setting. However, impact of varying price signals is not considered in applying DR [7].

Real time optimal scheduling of a battery energy storage system is proposed to reduce peak load of a building as an DSM technique to reduce cost of electrical energy in [8] and integration of renewable energy sources are not considered. Microgrid grid resources were integrated to the Indian distribution system and have been scheduled to reduce dependency on main grid and on the other hand peak loads were managed by means of flexible load shaping which is a tool of DSM minimizes the customer's dissatisfaction even diminished the operation cost of micro grid [9].

PEVs charging control is done based on a new distributed random-access approach which does not need centralized control and can be executed in real time. The work differs from the existing methodologies as it considers the historical data to coordinate smart agents rather than RTP [10]. Multi objective formulations were done in [11] to minimize total energy generation and cost associated for implementing DSM such that energy planning was done in a decentralized manner, PEVs charging is shifted resulted in reduction of total emissions and savings in cost.

Scheduling of PEVs at a building garage to reduce the peak load and energy cost is achieved in [12] by formulating an optimization model which minimizes the square of the Euclidean distance. Similarly, in a decentralized system, non-cooperative game approach is followed for obtaining charging and discharging schedules of the batteries and a distributed algorithm was developed where the total energy charging cost of a PEV is minimized. However, a pricing mechanism for vehicle to building model is not proposed, impact of discharging process of battery on its life is not evaluated, renewable energy sources integration is not considered. Dynamic pricing mechanism is one of the possible solutions to achieve DSM was worked out in [13] evaluated the effects of herding unusual participation of customers, laziness of customers, and different usage group of customers. Minimum size of the energy storage system is proposed in Plug in electric vehicle charging station supported by renewable energy sources [14].

Quadratic programming (QP) and multi agent system (MAS) approaches were discussed and compared by Mets et al. in [15] reduced the peak load and variability in the load of a distribution grid. MAS proved to be the best however QP results give more optimal solutions. However, EVs charged at off peak time can be helped to discharge their energy during peak periods back to the grid and vehicles arriving randomly to charge at the workplace are not considered. A micro grid consisting of wind, photovoltaic generation, utilized the stationary plug in hybrid electric vehicles by developing an optimal schedule for charging them to support the dynamic nature of renewable resources is proposed in [16]. A novel algorithm is proposed to charge large EV fleet by predicting their load day a head satisfying grid constraints, the individual requirements of the customer 
like arrival and departure times, by minimizing their overall charging cost, developing their individual plans in [17]. Particle swarm optimization is implemented to optimally schedule the EVs in a coordinated manner and minimized the active power losses compared to uncoordinated charging of EVs for an IEEE-33 bus radial system [18]. A meta heuristic algorithm used as optimization algorithm in [19] to optimize demand side of enhance time of use (ETOU) pricing for a commercial load demand and significantly analyzed that the technique shifted the maximum demand from peak time to off peak time which minimized the cost of electricity. Impacts of EV technology and how they help the world's growing demand for energy is demonstrated in [20].

Increase in number of EVs grows demand for electricity and to avoid interruptions in the grid, PV integration with EV charging station is presented thoroughly in [21]. Energy controller for micro grid is designed in [22] to develop charging and discharging schedules of EVs by absorbing over produced electricity with the integration of renewable energy and shaves the peak load of the micro grid.

This paper introduced an objective function to minimize the load variance and price indicated charging mechanism for controlled scheduling of EVs during valley hours. Finally results obtained in both the methods were compared and highlighted the best solution. The paper is outlined as follows: i) Section 2 consists of problem formulation, modelling of EV load; ii) Section 3 consists of two objective functions formulations; and iii) Section 4 summarizes the results by comparing both the scheduling schemes.

\section{PROBLEM FORMULATION}

The residential area under consideration is served by a $20 \mathrm{kVA}$ distribution transformer from the grid. It is having 8 houses and each house with an EV as shown in Figure 2, Each household load is the power consumed for lighting, air conditioner, washing machine, and water heater. and not including the EV load. The household load profile is adopted from [23] which is in fact considered from the website of electric reliability council of Texas (ERCOT), a South-Central Texas residential area. Basic household load profile of a day is shown in Figure 3

\subsection{Stochastic EV load modelling}

As EVs charging adds extra load to the distribution transformer there is a need to know about their daily travelling distances, estimating initial state of charge (SoC), starting time of charging to balance the energy and to avoid upgrading the existing transformer. To account uncertainties in the behavior of EV load, probabilistic distribution functions are used to estimate arrival time of the vehicle, distance travelled, initial SoC and time required to charge its battery. As per national household travel survey (NHTS) 2009 report which provides complete details of transportation in US, daily distance travelled by an EV follows Lognormal distribution and arrival time of the vehicle follows Gaussian distribution functions.

Distance travelled by most of the people is around 20-25 miles a day and more than half of the people travel less than 30 miles/day [23]. The travelled distance in miles per day can be approximated by Lognormal distribution given by (1) with mean $(\mu)$ of 3.37 and standard deviation $(\sigma)$ of 0.5 and it is shown in Figure 4

$$
\begin{gathered}
F_{d i s t}(d)=\frac{1}{d \sigma \sqrt{2 \pi}} e^{-(\ln d-\mu) / 2 \sigma^{2}} \text { for } d>0 \\
\% \text { of } s o c_{j}=\left[1-\left(E_{C} * d_{j}\right) / C_{b a t}\right] * 100
\end{gathered}
$$

Based on the distance travelled initial state of charge (SoC) of all EVs can be estimated as following from (2). Where $s o c_{j}$ is the initial soc of $j^{t h}$ vehicle. $d_{j}$ is the distance travelled in miles by $j^{\text {th }}$ vehicle. $E_{c}$ is the energy consumed in $\mathrm{kWh} /$ miles. $C_{b a t}$ is the battery capacity in $\mathrm{kWh}$. The EV model considered in this study is Nissan Leaf 2016 model, a car which solely runs on electricity with $24 \mathrm{kWh}$ battery capacity and having $0.28 \mathrm{kWh} / \mathrm{miles}$ consumption. Energy still required and time needed to charge the battery can be obtained as from (3) and (4).

$$
\operatorname{Ereq}_{j}=\frac{\operatorname{soc} f-s o c_{j}}{\eta} * C_{b a t}
$$

Where $\mathrm{Ereq}_{j}$ energy required to fill $j^{\text {th }}$ vehicle's battery in $\mathrm{kWh}, \eta$ is the efficiency of the charger which is considered as $0.95, S o C_{f}$ is the final SoC to be attained by the end of the charging and (4),

$$
C_{\text {time }}=\text { Ereq }_{j} / P
$$


where $C_{\text {time }}$ is the charging time required to charge battery in Hours, $\mathrm{P}$ is the output power of the charger in $\mathrm{kW}$. Since it is assumed charging EVs is done at residential area from [24], [25], level 1 charging output power is $1.44 \mathrm{~kW}(120 \mathrm{~V}, 12 \mathrm{~A})$ and for level 2 it is $3.3 \mathrm{~kW}(240 \mathrm{~V}, 14 \mathrm{~A})$ are considered. Most of the household owners charge their EVs after they return home from work at 16:00 to 21:00 according to NHTS 2009 report, the randomness in connecting EVs to start charging follows Gaussian distribution as given in (6) with a mean $(\eta)$ of 17:00 and standard deviation $(\sigma)$ of 2.28. The distribution function is described as follows and the distribution curve for arrival time of the EV is shown in Figure 5 .

$$
F_{A}(t)=\frac{1}{\sigma \sqrt{2 \pi}} e^{-(t-\mu) / 2 \sigma^{2}}, \text { for } 0<t<24
$$

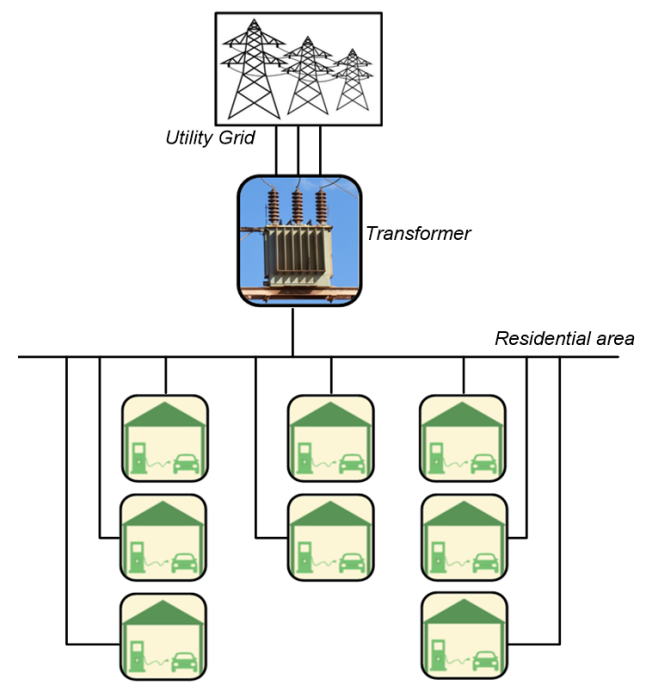

Figure 2. Residential area served by distribution transformer under study

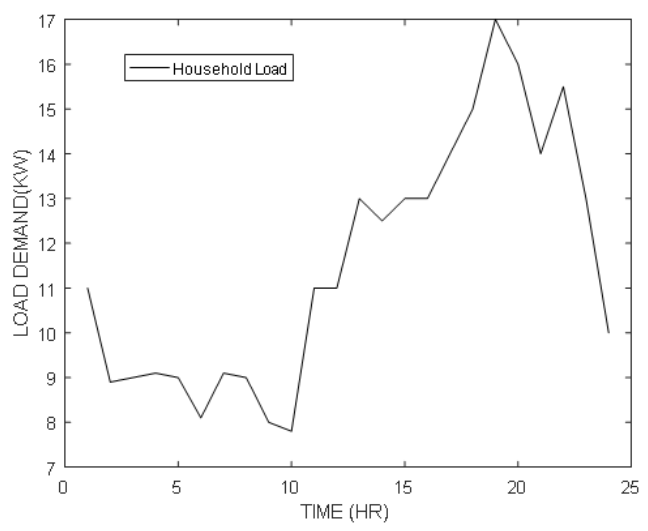

Figure 3. Household load profile of a day

To come up with randomness in the arrival time and distance travelled by the EVs random function is applied to their probability distribution function such that arrival time and distance travelled by each EV are obtained. The uncontrolled load curve which include EVs along with household load, household load and EV load are shown in Figure 6 and Figure 7 respectively for level 1 and level 2 charging. The uncontrolled load results from household load and EVs load when every household owner connects their EV immediately they arrive home. It is observed that from Figure 5 and Figure 6 due to uncontrolled charging of EVs distribution transformer is overloaded for 4 hours about $25 \%$ in level 1 whereas for almost 2 hours to $50 \%$ in level 2 charging. 


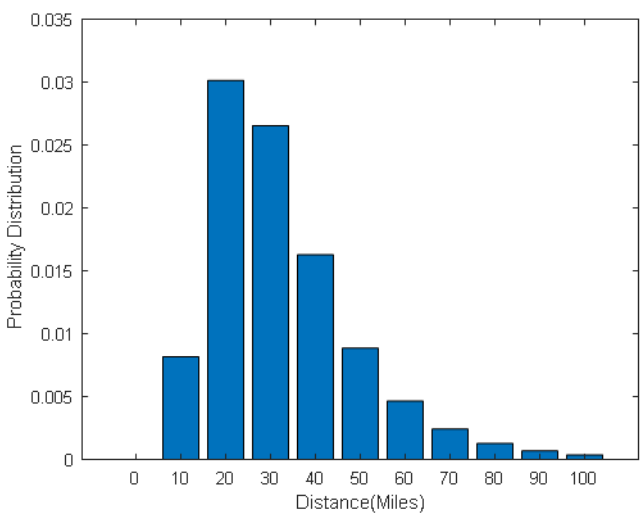

Figure 4. Distribution of distance travelled in miles

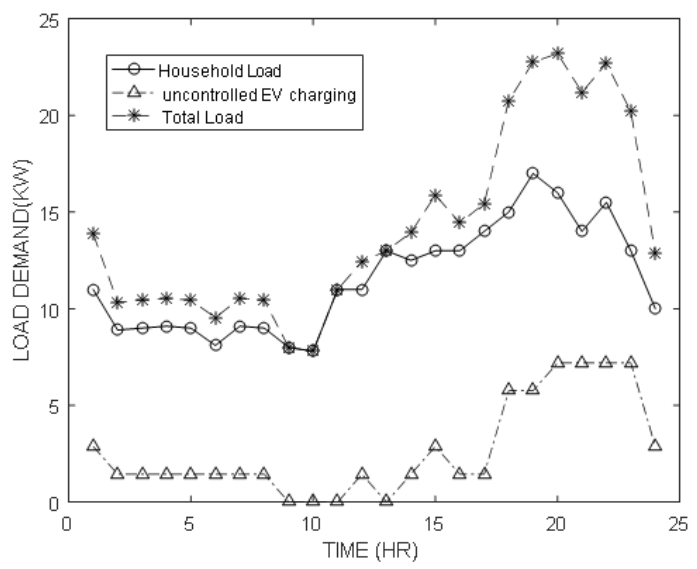

Figure 6. Uncontrolled charging of EVs overloading distribution transformer in level 1 charging

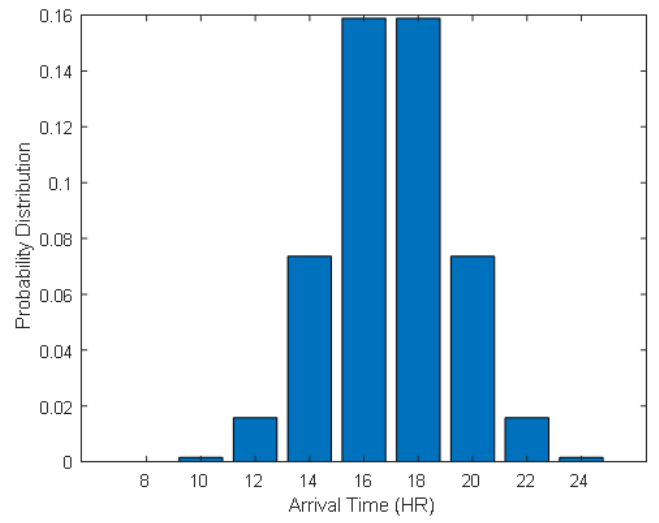

Figure 5. Distribution of arrival time of EVs

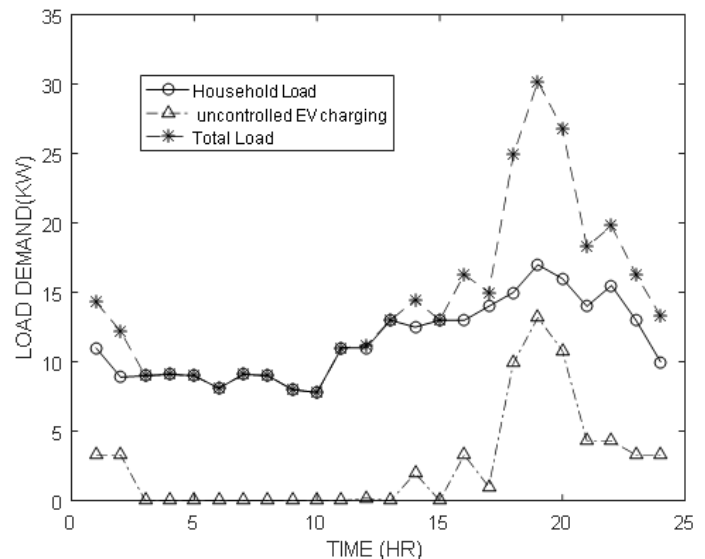

Figure 7. Uncontrolled charging of EVs overloading distribution transformer in level 2 charging

\section{OPTIMIZATION PROBLEMS FOR CONTROLLED CHARGING OF EVS}

In this section two objective function are designed based on DSM methodologies to control the charging of EVs such that optimal schedule of EVs are obtained which allows distribution transformer to operate within its capacity limits.

\subsection{Method 1: Minimizing load variance}

The idea behind this objective function is to reduce load during peak hours, flatten the load curve which minimizes the variance of energy required in a day. Minimizing the difference of load between off peak hours and peak hours helps the distribution transformer to function at high efficiency. Appropriate Scheduling of EVs achieves this objective more easily. The objective formulation of DSM can be expressed as follows and $\mathrm{EV}_{i j}$ is the optimization variable.

$$
\text { Minimize }\left\{\tau-\left[\sum_{i=1}^{24} \sum_{j=1}^{8}\left(H_{i j}+E V_{i j}\right)\right]\right\}^{2}
$$

Where $\tau$ is the total load profile to be met in a day in $\mathrm{kW} . H_{i j}$ is the $j^{\text {th }}$ home load profile at $i^{\text {th }}$ time period in $\mathrm{kW} . E V_{i j}$ is the charging power of the $j^{t h}$ vehicle at $i^{t h}$ time period in $\mathrm{kW}$.

$$
\text { and } \tau=\sum_{j=1}^{8}\left(\sum_{i=1}^{24} H_{i j}+\text { Ereq }_{j}\right)
$$


Subjected to following constraints,

$$
\begin{aligned}
& \forall j \quad \quad s o c_{j}+\sum_{i=t a}^{t d} E V_{i j} * \quad \eta \leq \text { Ereq }_{j} \\
& \forall i \text { and } \forall j \quad 0 \leq E V_{i j} \leq \operatorname{Emax}_{j} \\
& \forall i \quad \sum_{j=1}^{8}\left(H_{i j}+E V_{i j}\right) \leq P_{\text {trans }}
\end{aligned}
$$

where $S o c_{j}$ is the existing soc of the $j^{\text {th }}$ vehicle before it connects for charging in $\mathrm{kW} . \eta$ is the efficiency of the charger which is considered as 0.95. $E r e q_{j}$ charging power needed to fill $j^{\text {th }}$ vehicle's battery in kW. Emax is the power rating of the charger in $\mathrm{kW}$. $P_{\text {trans }}$ transformer load in $\mathrm{kW}$. ta,td are arrival and departure times respectively.

\subsection{Method 2: Price indicated charging mechanism}

The charging price of the EVs mainly depends on the fluctuations in the load. Prior information about electricity price helps consumers to shift their load from peak period to off peak period. The main aim of this objective is to shift load from peak hours to off peak hours with the help of a price indicator. Thus, this objective function schedules the charging of EVs more optimally without knowledge of real time prices such that it minimizes the charging cost of the EVs and prevents distribution transformer getting overloaded. Therefore, the objective function is (7),

$$
\operatorname{MIN}\left(\sum_{i=1}^{24} E_{i}+\sum_{i=1}^{24} \sum_{j=1}^{8} P_{i j} * C_{i}\right)
$$

where

$$
C_{i}=\delta_{i} / \delta_{T}
$$

and $E_{i}$ is the total household load profile at $i^{\text {th }}$ hour in $\mathrm{kW} . P_{i j}$ is the charging power of the $j^{\text {th }}$ vehicle at $i^{\text {th }}$ time period in $\mathrm{kW} . C_{i}$ is the price indicator which is the ratio of household load at $\mathrm{i}$ th period to the average household load of the day. $\delta_{i}$ is the household load at $\mathrm{i}$ th period in $\mathrm{kW} . \delta_{T}$ is the average household load of the day in $\mathrm{kW}$.

\section{SIMULATION RESULTS}

This section presents the results of the proposed optimization problems in two different charging levels. The proposed objectives are evaluated in LINGO platform. The aim is to achieve charging plan of each vehicle while satisfying the capacity of the distribution transformer capacity, minimizing the total cost of charging EVs and filling the batteries to $90 \%$ of the SoC. The optimization is performed on a residential area with household load, EV load obtained from stochastic modelling and the total load on distribution transformer based on uncontrolled charging of EVs. Here total load represents the sum of household load and EVs load. Figure 6 and Figure 7 presents the $20 \mathrm{kVA}$ distribution transformer overloading condition for level 1 and level 2 respectively for uncontrolled charging of EVs. Figure 8 and Figure 9 for level 1 and level 2 respectively shows the same after implementing the optimization for method 1 alleviating the problem of distribution transformer overload condition while satisfying the EV owner requirements like arrival time, departure time and ensuring that the battery reaches $90 \%$ of SoC.

The optimization problem in method 2 i.e. Price indicated charging mechanism is analysed on level 2 charging as more power is required to charge EVs in less duration when compared to level 1 and resulted in significant peaks as shown in Figure 7. The optimization results show that EVs load is scheduled such that the total load curve is well below within the rated capacity of distribution transformer which minimises the overall cost of the electricity. However off-peak hours from 1:00 to 8:00 are turned out to be peak hours which is treated as price indicated uncontrolled charging as shown in Figure 10.

From the household load profile of a day shown in Figure 3 off peak hours are from 1:00 to 10:00. Overall charging cost of EVs are further minimised by slightly adjusting the departure time of vehicles up to 10:00 am. Figure 11 shows the price indicated controlled charging of EVs.

Optimizing the effect of charging electric vehicles on distribution transformer using ... (Swapna Ganapaneni) 


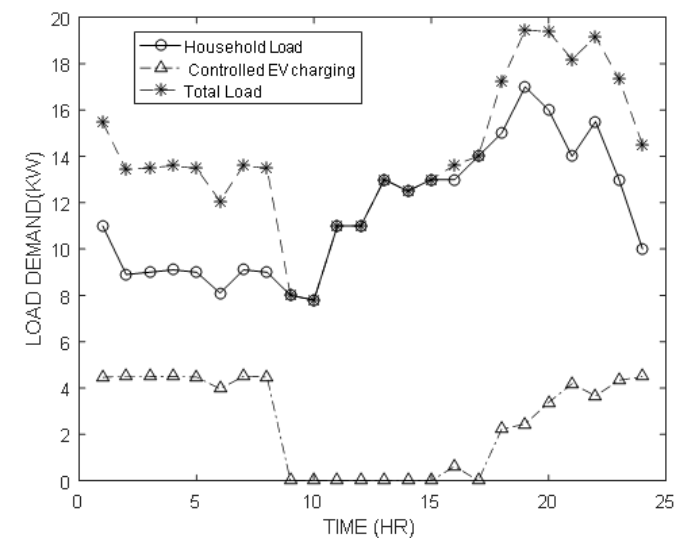

Figure 8. Controlled charging of EVs in level-1 alleviating overload condition of distribution transformer after minimising load variance

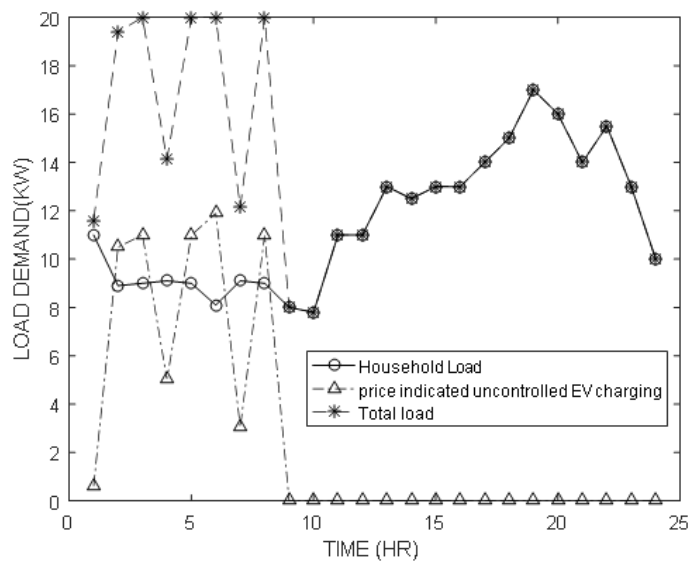

Figure 10. Price indicated uncontrolled charging mechanism for level 2 charging of EVs

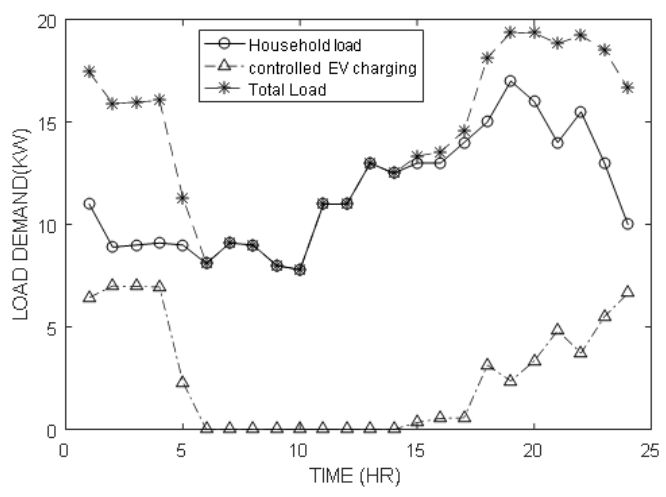

Figure 9. Controlled charging of EVs in level-2 alleviating overload condition of distribution transformer after minimising load variance

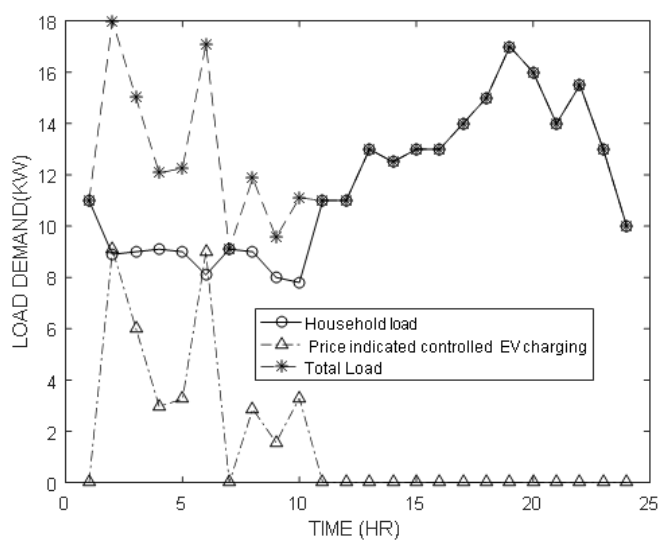

Figure 11. Price indicated controlled charging mechanism for level 2 charging of EVs

\subsection{Comparison of proposed optimization methods for level 2 charging}

The household load, EV load and total load of the distribution transformer when EVs are connected in level 2 charging mode based on uncontrolled charging, minimising load variance and price indicated charging mechanisms are presented in the Figure 12 and Figure 13 respectively. After performing the proposed optimization methods for DSM, without disturbing non EV load i.e household load by proper management of EVs, distribution transformer overloading problem is solved.

From the Figure 12 it can be observed that alone considering household load is well below the limits of the transformer but the total load of transformer along with household load when EVs are connected in uncontrolled manner overloaded the distribution transformer from 100 to $150 \%$ of its capacity for almost 3 hours during peak hours in the night. So, to minimize the load fluctuations and peak load the above implemented optimizations resulted in total load of controlled charging of EVs, total load of price indicated uncontrolled charging of EVs, total load of price indicated controlled charging of EVs. Out of which price indicated controlled charging of EVs balanced the system very well in terms of the total load on the transformer and in minimizing the charging price of the EVs. In price indicated uncontrolled charging though the total load on distribution transformer is well up to the capacity of transformer, off peak hours are loaded to full extent of the transformer capacity which may result in increase of charging prices of EVs compared to price indicated controlled charging. So, even though there is a slight violation in the departure times of vehicles price indicated controlled charging seems to be best when compared to controlled and price indicated uncontrolled charging. 
However, without having the knowledge of price fluctuations, not disturbing the household load while satisfying EV owner's requirements EVs load is scheduled in an optimal manner by adopting the transformer limits in minimizing the load variance optimization i.e method 1. Therefore, out of the three cases if price is not a constraint controlled charging of EVs, Price indicated uncontrolled charging yields the good solution to the residential area as well as to the distribution grid following all their requirements even optimizing the cost of charging EVs to most possible extent. Similarly, if there is minor flexibility considered in departure time of EVs above all price indicated controlled charging gives the best solution obeying the limits on the transformer as well as minimizing overall charging cost of EVs further proceeded to satisfy the EV owner requirements.

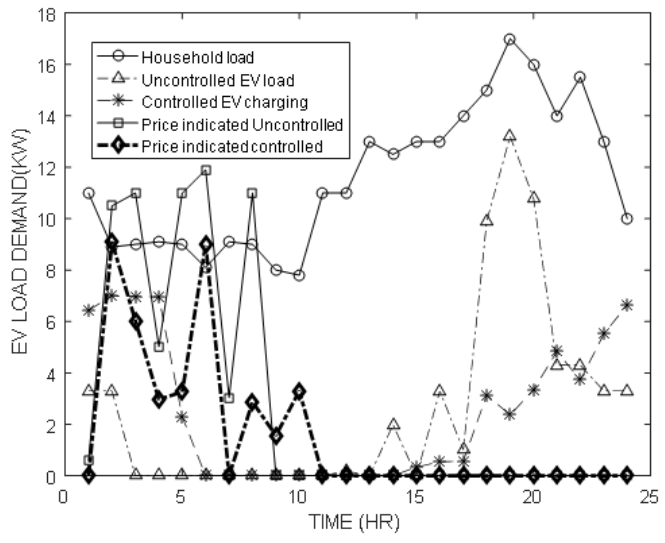

Figure 12. Household load, comparison of EV load of uncontrolled, controlled, price indicated uncontrolled, price indicated controlled for level 2 charging of EVs

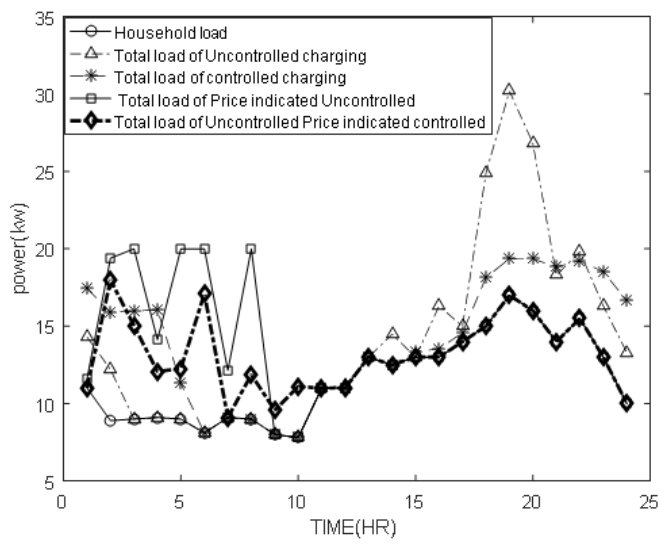

Figure 13. Household load, comparison of total load of uncontrolled, controlled, price indicated uncontrolled, price indicated controlled for level 2 charging of EVs

\section{CONCLUSION}

This paper firstly presented the methodology to model the stochastic EV load and total load at a residential area including EV load is calculated. As uncontrolled charging of EVs resulted in overloading of distribution transformer, demand side management techniques are implemented. The proposed optimization methods alleviated the problem of overloading transformer. Total load on the distribution transformer is compared in all the approaches. It is observed that method one minimized the load fluctuations by shifting EV load from peak hours to off peak hours and method two is implemented where EVs load is scheduled during low price hours and no knowledge on fluctuations in real time price is needed. Both methods satisfied the constraint on the transformer capacity, avoided peak load on the system, minimized the charging cost of EVs and scheduled them within the given time limit. We also presented the price indicated controlled charging mechanism which further optimized the charging price of EVs with slight deviation in departure times.

\section{REFERENCES}

[1] C. W. Gellings, "Evolving practice of demand-side management," Journal of modern power systems and clean energy, vol. 5, no. 1, pp. 1-9, 2017, doi: 10.1007/s40565-016-0252-1.

[2] M. C. Falvo, G. Graditi, and P. Siano, "Electric vehicles integration in demand response programs," in 2014 International Symposium on Power Electronics, Electrical Drives, Automation and Motion, 2014, pp. 548-553, doi: 10.1109/SPEEDAM.2014.6872126.

[3] P. Khajavi, H. Abniki, and A. Arani, "The role of incentive based demand response programs in smart grid," in 2011 10th International Conference on Environment and Electrical Engineering, 2011, pp. 1-4, doi: 10.1109/EEEIC.2011.5874702.

[4] J. Aghaei and M.-I. Alizadeh, "Demand response in smart electricity grids equipped with renewable energy sources: A review," Renewable and Sustainable Energy Reviews, vol. 18, pp. 64-72, 2013, doi: 10.1016/j.rser.2012.09.019.

[5] R. Aazami, S. Daniar, and V. Talaeizadeh, "Emergency demand response program modeling on power system reliability evaluation," Journal of Electrical Engineering, vol. 23, no. 4, pp. 151-157, 2016, doi: 10.6329/CIEE.2016.4.03.

[6] G. Gaur, N. Mehta, R. Khanna, and S. Kaur, "Demand side management in a smart grid environment," in 2017 IEEE International Conference on Smart Grid and Smart Cities (ICSGSC), 2017, pp. 227-231, doi: 10.1109/ICSGSC.2017.8038581.

[7] S. Shao, M. Pipattanasomporn, and S. Rahman, "Demand response as a load shaping tool in an intelligent grid with electric vehicles," IEEE Transactions on Smart Grid, vol. 2, no. 4, pp. 624-631, 2011, doi: 10.1109/TSG.2011.2164583. 
[8] M. Amoasi Acquah, D. Kodaira, and S. Han, "Real-time demand side management algorithm using stochastic optimization," Energies, vol. 11, no. 5, p. 1166, 2018, doi: 10.3390/en11051166.

[9] S. Paul, A. Tamrakar, and N. P. Padhy, "Demand side management based optimal scheduling portfolio of a microgrid in linear programming platform," in 2018 20th National Power Systems Conference (NPSC), 2018, pp. 1-6, doi: 10.1109/NPSC.2018.8771711.

[10] K. Zhou and L. Cai, "A decentralized access control algorithm for PHEV charging in smart grid," Energy Systems, vol. 5, no. 4, pp. 607-626, 2014, doi: 10.1007/s12667-013-0092-2.

[11] B. Ramachandran and A. Ramanathan, "Decentralized demand side management and control of pevs connected to a smart grid," in 2015 Clemson University Power Systems Conference (PSC), 2015, pp. 1-7, doi: 10.1109/PSC.2015.7101679.

[12] H. K. Nguyen and J. B. Song, "Optimal charging and discharging for multiple phevs with demand side management in vehicle-tobuilding," Journal of Communications and networks, vol. 14, no. 6, pp. 662-671, Dec. 2012, doi: 10.1109/JCN.2012.00032.

[13] T. K. Wijaya, T. G. Papaioannou, X. Liu, and K. Aberer, "Effective consumption scheduling for demand-side management in the smart grid using non-uniform participation rate," in 2013 Sustainable Internet and ICT for Sustainability (SustainIT), 2013, pp. 1-8, doi: 10.1109/SustainIT.2013.6685188.

[14] M. Shaaban, A. Eajal, and E. El-Saadany, "Coordinated charging of plug-in hybrid electric vehicles in smart hybrid AC/DC distribution systems," Renewable Energy, vol. 82, pp. 92-99, 2015, doi: 10.1016/j.renene.2014.08.012.

[15] K. Mets, R. D'hulst, and C. Develder, "Comparison of intelligent charging algorithms for electric vehicles to reduce peak load and demand variability in a distribution grid," Journal of Communications and Networks, vol. 14, no. 6, pp. 672-681, Dec. 2012, doi: 10.1109/JCN.2012.00033.

[16] K. Vijay Kumar and T. Bharath Kumar, "Optimal scheduling of micro grid for plug-in electrical vehicle," International Journal of Engineering and Technology (UAE), vol. 7, no. 2.7, pp. 558-564, 2018, doi: 10.14419/ijet.v7i2.7.10882.

[17] O. Sundström and C. Binding, "Planning electric-drive vehicle charging under constrained grid conditions," in 2010 International Conference on Power System Technology, 2010, pp. 1-6, doi: 10.1109/POWERCON.2010.5666620.

[18] W. I. F. W. Zalnidzam, H. Mohamad, N. A. Salim, H. Mokhlis, and Z. M. Yasin, "Optimal charging schedule coordination of electric vehicles in smart grid," Indonesian Journal of Electrical Engineering and Computer Science (IJEECS), vol. 11, no. 1, pp. 82-89, 2018, doi: 10.11591/ijeecs.v11.i1.pp82-89.

[19] M. Sulaima, N. Dahlan, Z. Yasin, N. Asari, and Z. Bohari, "Optimum enhance time of use (ETOU) for demand side electricity pricing in regulated market: An implementation using evolutionary algorithm," Indonesian Journal of Electrical Engineering and Computer Science (IJEECS), vol. 8, no. 1, pp. 253-261, 2017, doi: 10.11591/ijeecs.v8.i1.pp253-261.

[20] W. A. Salah et al., "Electric vehicle technology impacts on energy," International Journal of Power Electronics and Drive Systems (IJPEDS), vol. 10, no. 1, pp. 1-9, 2019, doi: 10.11591/ijpeds.v10.i1.pp1-9.

[21] A. R. Bhatti, Z. Salam, M. J. B. Abdul, and K. P. Yee, "A comprehensive overview of electric vehicle charging using renewable energy," International Journal of Power Electronics and Drive Systems (IJPEDS), vol. 7, no. 1, pp. 114-123, 2016, doi: 10.11591/ijpeds.v7.i1.pp114-123.

[22] J. Lee and G.-L. Park, "Integrated coordination of electric vehicle operations and renewable energy generation in a microgrid," International Journal of Electrical and Computer Engineering (IJECE), vol. 7, no. 2, pp. 706-712, 2017, doi: 10.11591/ijece.v7i2.pp706712.

[23] C. M. Affonso and M. Kezunovic, "Probabilistic assessment of electric vehicle charging demand impact on residential distribution transformer aging," in 2018 IEEE International Conference on Probabilistic Methods Applied to Power Systems (PMAPS), 2018, pp. 1-6, doi: 10.1109/PMAPS.2018.8440211.

[24] C. Pang, P. Dutta, S. Kim, M. Kezunovic, and I. Damnjanovic, "Phevs as dynamically configurable dispersed energy storage for v2b uses in the smart grid," 2010, doi: 10.1049/cp.2010.0903.

[25] S. S. Raghavan and A. Khaligh, "Impact of plug-in hybrid electric vehicle charging on a distribution network in a smart grid environment," in 2012 IEEE PES Innovative Smart Grid Technologies (ISGT), 2012, pp. 1-7, doi: 10.1109/ISGT.2012.6175632.

\section{BIOGRAPHIES OF AUTHORS}

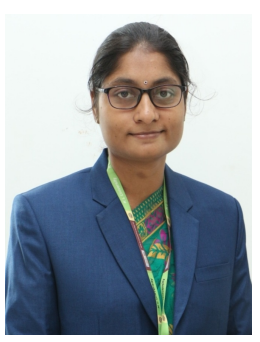

Mrs. Ganapaneni Swapna (D) 5 P Porking as Assistant professor in the department of Electrical and Electronics Engineering at K L Deemed to be university(KLEF) in the area of Power systems control and Automation. She obtained her B.Tech and M.Tech degree from JNTU Kakinada and currently pursuing $\mathrm{PhD}$ in KLEF. She is having nine years of teaching experience. Her research interests include power systems deregulation and optimal charging of Electric vehicles in smart grid. She published 7 articles in SCI and Scopus indexed journals. She is affiliated with IEEE as student member and ACM as professional member. She can be contacted at email: swapna@kluniversity.in.

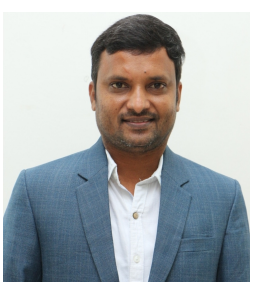

Dr. Pinni Srinivasa Varma (D) IS P completed his M. Tech. from JNTU Hyderabad. He has completed his Ph.D. from JNTU Anantapur. His areas of research are Power System Deregulation and Power System Reliability. He has published 50 research papers in various international journals. He has written a textbook on Power System Deregulation and is published by Lambert publishers. He has published 2 patents in the area of Power Systems. Now, he is working as Associate Professor in EEE Dept., K L University, Guntur, Andhra Pradesh, India. At present Dr. P S Varma is serving as Associate Dean RD, KLEF. He can be contacted at email: pinnivarma@kluniversity.in. 